\title{
Knowledge and Practices Related to Salt Intake among Saudi Adults
}

\author{
Mahitab A. Hanbazaza ${ }^{1}$ and Walaa A. Mumena ${ }^{2, *(D)}$ \\ 1 Department of Food and Nutrition, Faculty of Human Sciences and Design, King Abdulaziz University, \\ P.O. Box 80200, Jeddah 21589, Saudi Arabia; mhanbazaza@kau.edu.sa \\ 2 Clinical Nutrition Department, College of Applied Medical Sciences, Taibah University, P.O. Box 344, \\ Madinah 42353, Saudi Arabia \\ * Correspondence: wmumena@taibahu.edu.sa; Tel.: +966-530819399
}

Received: 8 July 2020; Accepted: 6 August 2020; Published: 9 August 2020

\begin{abstract}
In Saudi Arabia, data regarding salt-related knowledge and practices are still lacking. This cross-sectional study aimed to investigate salt-related knowledge and practices and associated factors in Saudi adults. Data on the following variables were collected from 467 participants living in Madinah or Jeddah via face-to-face interviews: demographics, anthropometrics (height and weight), blood pressure (assessed using a digital sphygmomanometer), salt-related knowledge, and practices related to salt intake. Salt-related knowledge and practices were limited among the study participants; however, they were not correlated $\left(\mathrm{r}_{\mathrm{s}}=0.10\right)$. Multiple linear regression analysis revealed that salt-related practices were negatively associated with sodium intake and positively associated with body mass index (BMI) $(p<0.001$ and $p=0.001$, respectively), whereas salt-related knowledge was not associated with sodium intake, blood pressure, or BMI. Salt-related knowledge is limited and not linked to practices related to salt intake in Saudi adults. Interventions are needed to increase the accessibility of low-sodium food options and improve practices limiting sodium intake to prevent the occurrence of salt-related diseases among adults in Saudi Arabia.
\end{abstract}

Keywords: knowledge; practices; salt intake; adults; Saudi Arabia

\section{Introduction}

Salt is a common form of sodium, and previous studies have revealed that it is consumed excessively in many populations, including that of Saudi Arabia [1,2]. High levels of sodium consumption are associated with many chronic diseases, such as hypertension (HTN) and cardiovascular disease (CVD) [3-5]. In fact, excessive sodium intake is known as a silent killer, and it is responsible for approximately 2.5 million deaths annually [6,7]. In Saudi Arabia, CVD is one of the most common causes of death [8]. To limit sodium intake and prevent salt-related diseases, several organizations recommend sodium intake limits. For example, the American Heart Association (AHA) recommends restraining sodium intake to less than $2300 \mathrm{mg}$ of sodium per day [9].

Food sources of sodium vary across populations [5]. Despite the differences in the eating habits of individuals, processed and restaurant-prepared food have been reported to largely contribute to high sodium intake $[10,11]$. In the Gulf Cooperation Council countries (Saudi Arabia, Bahrain, Kuwait, the United Arab Emirates, Oman, and Qatar), bread was determined to be the principal source of salt in the diets of individuals in 2015 [12]. Furthermore, recent evidence has shown that a large proportion of the food consumed by Saudis is processed food that is high in sodium [2,13].

Other factors such as sex and awareness of the health consequences of excessive intake of sodium are also linked to excessive sodium intake [14]. Limited awareness of the health consequences of excessive sodium intake has been reported in a number of populations [2,15]. Salt-related knowledge 
is important, because it likely affects the practices associated with reducing the levels of salt in the diet $[16,17]$. Reducing salt intake significantly decreases the risk of CVD and stroke, improves health outcomes, and reduces mortality rates $[18,19]$. Improving an individual's understanding of healthy eating habits and the health consequences of a poor diet has been found to be an effective means of influencing eating behaviors and practices [20].

The World Health Organization (WHO) recommends the evaluation of individuals' knowledge and practices related to salt intake in order to plan interventions that aim to reduce salt intake [20]. In Saudi Arabia, data regarding salt-related knowledge and practices are still lacking. Thus, this study aimed to investigate salt-related knowledge and practices and the associated factors among Saudi adults.

\section{Materials and Methods}

\subsection{Sample}

This cross-sectional study included 494 healthy participants aged between 20 and 50 years who were recruited conveniently between January and March 2020 from two large cities, Madinah and Jeddah, in the Western region of Saudi Arabia. Participants were recruited from public places in both cities, including malls, parks, Jeddah Corniche, and walking paths. Male participants from Madinah who expressed interest in participating in the study, but were not able to provide data at the time, were invited to visit the Home Care Service Center in Madinah, Saudi Arabia. Pregnant women; individuals with diabetes, HTN, or CVD; and individuals with a history of bariatric surgery, those following a special diet, or those taking any medication that might influence blood pressure or weight were excluded. Individuals who reported participating in moderate- or high-intensity physical activity at the time of data collection were also excluded. Data on all participants were collected via face-to-face interviews at data collection stations. Participants were asked to provide data regarding their age, sex (male; female), marital status (single; married), education level (high-school/diploma; university degree/postgraduate degree), family income per month ( $<$ SR 5000; SR 5000-10,000; $>$ SR 10,000), and city of residence (Jeddah; Madinah). Ethical approval for the study was obtained from the Ethical Committee of the College of Applied Medical Sciences, Taibah University (certificate number: SREC/AMS 2019/33/CND). Signed consent forms were obtained from all participants prior to data collection.

\subsection{Sodium Intake}

Dietary sodium intake was assessed using a semi-validated food frequency questionnaire (FFQ) [21]. The FFQ was used to evaluate the quantity of sodium naturally present in food and the quantity added during cooking, but not sodium coming from table salt. The FFQ was specifically developed to assess sodium intake in the Saudi population. The sodium content in food was estimated by the Nutritics software ${ }^{\circledR}$ (version 5.09, Libro, Dublin, Ireland). Information of local food items and recipes were manually added into the Nutritics software. The sodium contents of all listed food items were validated based on the sodium contents of local products.

\subsection{Assessment of Anthropometric Measurements}

The height and weight of each participant were measured thrice using standardized procedures, and the average values were recorded. Weight was assessed using a portable electronic scale (Omron, BF508, Japan), and values were recorded to the nearest $0.1 \mathrm{~kg}$. Height was assessed using a measuring tape placed on a straight wall, and values were recorded to the nearest $0.5 \mathrm{~cm}$. Weight and height measurements were used to estimate the body mass index (BMI) of each participant, and weight status was determined in accordance with the WHO criteria [22]. All participants were provided with cards containing the following information: date of data collection, height, weight, BMI, and blood pressure readings. 


\subsection{Assessment of Blood Pressure}

A digital sphygmomanometer (Cardio Simple, Pic Solutions, Casnate Con Bernate, Italy) was used to assess blood pressure after it was calibrated and validated appropriately. Blood pressure was measured using standardized procedures after participants had been instructed to relax and sit calmly for 5 minutes. Blood pressure measurements were taken thrice at 5-minute intervals, and the average readings were recorded. Blood pressure cutoff values were specified based on 17 American College of Cardiology (ACC)/AHA guidelines: normal blood pressure are $<120 / 80 \mathrm{~mm} \mathrm{Hg}$; elevated blood pressure, systolic blood pressure values between 120 and $129 \mathrm{~mm} \mathrm{Hg}$ and diastolic blood pressure values < $80 \mathrm{~mm} \mathrm{Hg}$; stage 1 hypertension, systolic blood pressure values between 130 and $139 \mathrm{~mm}$ $\mathrm{Hg}$ or diastolic blood pressure values between 80 and $89 \mathrm{~mm} \mathrm{Hg}$; stage 2 hypertension, systolic blood pressure values of at least $140 \mathrm{~mm} \mathrm{Hg}$ or diastolic blood pressure values of at least $90 \mathrm{~mm}$ $\mathrm{Hg}$ [23]. If high blood pressure was observed, participants were advised to visit a physician to perform additional tests, receive counsel, and receive treatment if needed.

\subsection{Assessment of Salt-Related Knowledge}

Salt-related knowledge was assessed using the following 5 questions that were adapted from a study conducted by Ismail et al. (2019) (accounting for a total score of 5) [24]: (1) Could high salt intake adversely affect health? (2) Could high salt intake increase the risk of HTN? (3) Could high salt intake increase the risk of osteoporosis? (4) Could high salt intake increase the risk of stomach cancer? and (5) Could high salt intake increase the risk of kidney stones? Participants were allowed to select between "yes" or "no" when answering each question. Correct answers to all questions were "yes". Variables were converted to numerical scale where a score of one was assigned to the total knowledge score variable for every correct answer. When participants gave a wrong answer, a score of zero was assigned.

\subsection{Assessment of Salt-Related Practices}

Practices related to salt intake were assessed based on positive behaviors with respect to 6 items that were also adapted from Ismail et al. (accounting for a total score of 6) [24]. Item one focused on sodium intake; a score of one was assigned if the participant's sodium intake was within the limit recommended by the AHA ( $<2300 \mathrm{mg} /$ day), whereas a score of zero was assigned the participant's sodium intake that exceeded the sodium recommendation. The second item focused on the addition of salt during cooking; a score of one was assigned if salt was never, rarely, or sometime added to the food during cooking, while a score of zero was assigned if salt was frequently added to the food during cooking. The third item focused on the use of table salt; a score of one was assigned if salt was never, rarely, or sometime added at the table, while a score of zero was assigned if salt was frequently added at the table. Responses to items two and three were "never"; "rarely"; "sometime"; "usually"; and "always". The fourth item focused on the effort made to reduce salt intake; a score of one was assigned if the participant made an effort to reduce salt intake, while a score of zero was assigned if the participant did not report making an effort to reduce salt intake. The fifth item focused on the use of salt alternatives; a score of one was assigned if the participant reported using salt alternatives, while a score of zero was assigned if the participant did not report using salt alternatives. Responses to items 4 and 5 were "yes" and "no". The sixth item focused on limiting fast food consumption; a score of one was assigned if the frequency of fast food consumption was $\leq 1$ instance/week, while a score of zero was assigned if the frequency of fast food consumption was $\geq 2$ instance/week. To assess the frequency of fast food consumption, participants were asked to report the frequency of their usual fast food consumption in a typical week.

\subsection{Statistical Analysis}

Descriptive data were presented as means (standard deviations (SD)) for symmetric continuous variables, medians (interquartile ranges (IQR)) for asymmetric continuous variables, and frequencies (percentages (\%)) for categorical variables. A chi-square test was used to assess whether there was an 
association between two categorical variables. Spearman correlation was used to assess the associations between the total scores of salt-related knowledge and salt reduction practices. The and Kruskal-Wallis and Mann-Whitney $U$ tests were used to assess whether the differences across groups were significant. Multiple linear regression analysis was performed to determine the association between the total score of salt-related knowledge and sodium intake, blood pressure, and BMI after adjusting for sex (male $=1$ and female $=2$ ). In addition, multiple linear regression models were used to explore the association between the total score of salt-related practices and sodium intake, blood pressure, and BMI. These models were adjusted for age, sex (male $=1$ and female $=2$ ), marital status (single $=0$ and married $=1$ ), and city of residence (Madinah $=1$ and Jeddah $=2$ ). The assumptions of multiple linear regression analysis were evaluated and met. All tests performed were two-tailed and a significance level of 0.05 was used. Statistical analyses were performed using the Statistical Package for the Social Sciences (SPSS 20, SPSS Inc, Chicago, IL, USA).

\section{Results}

The total number of healthy participants included in this study was 467 after the exclusion of participants with missing data $(n=27,5.47 \%)$. Over three-quarters of the participants $(n=368)$ were recruited from Madinah. The mean age of the study participants was $29.0(9.10)$ years, and $60 \%(n=281)$ were female. The median sodium intake was 4273 (IQR: 3053-5979) mg/day. The mean BMI was 25.86 (5.81) kg/m², which was categorized as overweight. The mean systolic blood pressure and diastolic blood pressure values were 119 (12.0) and 80.6 (9.32) $\mathrm{mm} \mathrm{Hg}$, respectively. A detailed description of the sociodemographic and physical characteristics of the study participants is provided in Table 1.

Table 1. Sociodemographic and physical characteristics of the participants $(n=467)$.

\begin{tabular}{|c|c|c|}
\hline Characteristics & $n$ & $(\%)$ \\
\hline \multicolumn{3}{|l|}{ Age (years) } \\
\hline $20-29$ & 294 & 63.0 \\
\hline $30-39$ & 91 & 19.5 \\
\hline$\geq 40$ & 82 & 17.5 \\
\hline \multicolumn{3}{|l|}{ Sex } \\
\hline Male & 186 & 39.8 \\
\hline Female & 281 & 60.2 \\
\hline \multicolumn{3}{|l|}{ Marital status } \\
\hline Single & 196 & 42.0 \\
\hline Married & 271 & 58.0 \\
\hline \multicolumn{3}{|l|}{ Education level } \\
\hline High-school/Diploma & 229 & 49.0 \\
\hline University degree/Postgraduate degree & 238 & 51.0 \\
\hline \multicolumn{3}{|l|}{ Family income (SR) } \\
\hline$<5000$ & 243 & 52.0 \\
\hline $5000-10,000$ & 102 & 21.9 \\
\hline$>10,000$ & 122 & 26.1 \\
\hline \multicolumn{3}{|l|}{ City of residence } \\
\hline Madinah & 368 & 78.8 \\
\hline Jeddah & 99 & 21.2 \\
\hline \multicolumn{3}{|l|}{ Weight status (BMI in $\mathrm{kg} / \mathrm{m}^{2}$ ) } \\
\hline Underweight $(<18.5)$ & 40 & 8.57 \\
\hline Healthy weight (18.5-24.99) & 179 & 38.3 \\
\hline Overweight (25-29.99) & 122 & 26.1 \\
\hline Obese $(\geq 30)$ & 126 & 27.0 \\
\hline \multicolumn{3}{|l|}{ Blood pressure (mm Hg) } \\
\hline Normal $(<120 / 80)$ & 158 & 33.8 \\
\hline Elevated (systolic 120-129 and diastolic <80) & 42 & 8.99 \\
\hline Stage 1 hypertension (systolic $130-139$ or diastolic $80-89$ ) & 186 & 39.8 \\
\hline Stage 2 hypertension (systolic $>140$ or diastolic $\geq 90$ ) & 81 & 17.3 \\
\hline
\end{tabular}

SR: Saudi Riyal (SR 3.75 = \$1.00); BMI: body mass index. 
The median salt-related knowledge score was 3.00 (IQR 3.00-4.00) out of 5.00, whereas the median salt-related practices score was 1.00 (IQR 1.00-2.00) out of 6.00. Spearman correlation between salt-related knowledge and practices was weak $\left(r_{s}=0.10, p=0.036\right)$. An assessment of salt-related knowledge and practices according to sex revealed that higher proportion of female participants recognized the effect of high salt intake on health $(p<0.001)$. In addition, higher proportion of female participants responded correctly to the questions regarding high salt intake and the increased risk of HTN and kidney stones ( $p=0.006$ and $p<0.001$, respectively). Lower proportion of female participants reported frequent consumption of fast food $(p<0.001)$, as shown in Table 2.

Table 2. Salt-related knowledge and practices stratified by sex $(n=467)$.

\begin{tabular}{|c|c|c|c|c|c|}
\hline & Variable & $\begin{array}{c}\text { Males } \\
(n=186)\end{array}$ & $\begin{array}{l}\text { Females } \\
(n=281)\end{array}$ & $\begin{array}{c}\text { Total } \\
(n=467)\end{array}$ & $p$ \\
\hline \multicolumn{6}{|c|}{ Salt-related knowledge } \\
\hline \multirow[t]{2}{*}{1} & Could high salt inta & re in the die & rsely affect & lth? & \multirow[b]{2}{*}{$0.002 *$} \\
\hline & $\begin{array}{l}\text { Yes }{ }^{a} \\
\text { No }\end{array}$ & $\begin{array}{c}169(90.9) \\
17(9.10)\end{array}$ & $\begin{array}{c}274(97.5) \\
7(2.50)\end{array}$ & $\begin{array}{c}443(94.9) \\
24(5.10)\end{array}$ & \\
\hline \multicolumn{6}{|c|}{ Could high salt intake increase the risk for ...... } \\
\hline 2 & $\begin{array}{l}\text { Hypertension? } \\
\text { Yes }^{\text {a }} \\
\text { No }\end{array}$ & $\begin{array}{c}163(87.6) \\
23(12.4)\end{array}$ & $\begin{array}{c}262(93.2) \\
19(6.80)\end{array}$ & $\begin{array}{c}425(91.0) \\
42(9.00)\end{array}$ & $0.038 *$ \\
\hline 3 & $\begin{array}{l}\text { Osteoporosis? } \\
\text { Yes }^{\text {a }} \\
\text { No }\end{array}$ & $\begin{array}{c}23(12.4) \\
163(87.6)\end{array}$ & $\begin{array}{c}35(12.5) \\
246(87.5)\end{array}$ & $\begin{array}{c}58(12.4) \\
409(87.6)\end{array}$ & 0.977 \\
\hline 4 & $\begin{array}{l}\text { Stomach cancer? } \\
\text { Yes }^{\text {a }} \\
\text { No }\end{array}$ & $\begin{array}{c}9(4.80) \\
117(95.2)\end{array}$ & $\begin{array}{c}15(5.30) \\
266(94.7)\end{array}$ & $\begin{array}{c}24(5.10) \\
443(94.9)\end{array}$ & 0.811 \\
\hline 5 & $\begin{array}{l}\text { Kidney stones? } \\
\text { Yes }^{\text {a }} \\
\text { No }\end{array}$ & $\begin{array}{c}70(37.6) \\
116(62.4)\end{array}$ & $\begin{array}{l}155(55.2) \\
126(44.8)\end{array}$ & $\begin{array}{l}225(48.2) \\
242(51.8)\end{array}$ & $<0.001 *$ \\
\hline \multicolumn{6}{|c|}{ Salt-related practices } \\
\hline 1 & $\begin{array}{l}\text { Sodium intake within the } \\
\text { recommendation of the American } \\
\text { Heart Association }(<2,300 \mathrm{mg} / \text { day }) \\
\text { Sodium intake above the } \\
\text { recommendation of the American } \\
\text { Heart Association }(\geq 2,300 \mathrm{mg} / \text { day) }\end{array}$ & $171(91.9)$ & $252(89.7)$ & $44(9.40)$ & 0.414 \\
\hline 2 & $\begin{array}{c}\text { Addition of salt to food during cooking } \\
\text { Always/Usually/Sometime } \\
\text { Rarely/Never }\end{array}$ & $\begin{array}{c}177(95.2) \\
9(4.80)\end{array}$ & $\begin{array}{c}270(96.1) \\
11(3.90)\end{array}$ & $\begin{array}{c}447(95.7) \\
20(4.30)\end{array}$ & 0.629 \\
\hline 3 & $\begin{array}{c}\text { Addition salt to food at the table } \\
\text { Always/Usually/Sometime } \\
\text { Rarely/Never }\end{array}$ & $\begin{array}{c}46(24.7) \\
140(75.3)\end{array}$ & $\begin{array}{c}49(17.5) \\
231(82.5)\end{array}$ & $\begin{array}{c}95(20.4) \\
371(79.6)\end{array}$ & 0.058 \\
\hline 4 & $\begin{array}{c}\text { Previously tried reducing salt intake } \\
\text { Yes } \\
\text { No }\end{array}$ & $\begin{array}{c}75(40.3) \\
111(59.7)\end{array}$ & $\begin{array}{l}134(47.7) \\
147(52.3)\end{array}$ & $\begin{array}{l}209(44.8) \\
258(55.2)\end{array}$ & 0.117 \\
\hline
\end{tabular}


Table 2. Cont.

\begin{tabular}{cccccc}
\hline Variable & $\begin{array}{c}\text { Males } \\
(\boldsymbol{n}=\mathbf{1 8 6})\end{array}$ & $\begin{array}{c}\text { Females } \\
(\boldsymbol{n}=\mathbf{2 8 1})\end{array}$ & $\begin{array}{c}\text { Total } \\
(\boldsymbol{n}=\mathbf{4 6 7 )}\end{array}$ & $p$ \\
\hline 5 & Previously tried using salt alternatives & & & & \\
Yes & $2(1.10)$ & $12(4.30)$ & $14(3.00)$ & $0.047^{*}$ \\
\hline & No & $184(98.9)$ & $269(95.7)$ & $453(97.0)$ & \\
\hline 6 & Fast food consumption & & & & \\
& $\begin{array}{c}\text { Once a week or less } \\
\text { Twice a week or more }\end{array}$ & $41(22.0)$ & $131(46.6)$ & $172(36.8)$ & $<0.001^{*}$ \\
\hline
\end{tabular}

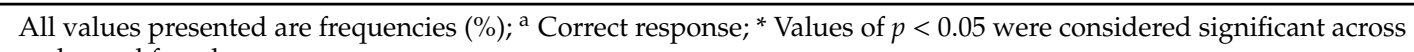
males and females.

Only 11 participants $(2.36 \%)$ scored 5 out of 5 on the assessment of salt-related knowledge; 168 $(36.0 \%)$ participants scored 4 out of 5 . One participant $(0.21 \%)$ scored 5 out of 5 on the assessment of items concerning practices related to salt intake, and 13 participants $(2.78 \%)$ scored 4 out of 5 . The scores of salt-related knowledge and practices were significantly higher among female participants than among male participants $(p<0.001)$. The scores of practices related to salt intake were significantly higher among older participants (age $\geq 40$ years) and among participants who were obese $(p<0.001$ and $p=0.001$, respectively). Additionally, participants who were married and those living in Madinah had high mean scores for salt-related practices ( $p<0.001$ and $p=0.043$, respectively). The associations between salt-related knowledge and practices and the characteristics of participants are presented in Table 3.

Table 3. Association between salt-related knowledge and practices and sociodemographic and physical characteristics $(n=467)$.

\begin{tabular}{|c|c|c|}
\hline Characteristics & $\begin{array}{c}\text { Knowledge Score Out of } 5 \\
\text { Mean (SD) }\end{array}$ & $\begin{array}{c}\text { Practice Score Out of } 6 \\
\text { Mean (SD) }\end{array}$ \\
\hline \multicolumn{3}{|c|}{ Age (years) } \\
\hline $20-29$ & $3.29(0.79)$ & $1.60(0.96)$ \\
\hline $30-39$ & $3.16(0.73)$ & $1.73(0.99)$ \\
\hline$\geq 40$ & $3.32(0.66)$ & $2.37(0.94)$ \\
\hline$p$-value & 0.211 & $<0.001 *$ \\
\hline \multicolumn{3}{|c|}{ Sex } \\
\hline Male & $3.09(0.83)$ & $1.50(0.94)$ \\
\hline Female & $3.39(0.68)$ & $1.93(1.00)$ \\
\hline$p$-value & $<0.001 *$ & $<0.001 *$ \\
\hline \multicolumn{3}{|c|}{ Marital status } \\
\hline Single & $3.25(0.74)$ & $1.97(1.00)$ \\
\hline Married & $3.28(0.78)$ & $1.60(0.97)$ \\
\hline$p$-value & 0.653 & $<0.001 *$ \\
\hline \multicolumn{3}{|c|}{ Education level } \\
\hline High-school/Diploma & $3.24(0.77)$ & $1.74(0.96)$ \\
\hline University degree/Postgraduate degree & $3.29(0.75)$ & $1.78(1.04)$ \\
\hline$p$-value & 0.536 & 0.684 \\
\hline \multicolumn{3}{|c|}{ Family income (SR) } \\
\hline$<5000$ & $3.29(0.76)$ & $1.69(1.01)$ \\
\hline $5000-10,000$ & $3.14(0.81)$ & $1.80(0.96)$ \\
\hline$>10,000$ & $3.33(0.72)$ & $1.85(1.01)$ \\
\hline$p$-value & 0.205 & 0.313 \\
\hline \multicolumn{3}{|c|}{ City of residence } \\
\hline Madinah & $3.24(0.73)$ & $1.80(0.97)$ \\
\hline Jeddah & $3.35(0.82)$ & $1.57(1.10)$ \\
\hline$p$-value & 0.178 & $0.043 *$ \\
\hline
\end{tabular}


Table 3. Cont.

\begin{tabular}{|c|c|c|}
\hline Characteristics & $\begin{array}{c}\text { Knowledge Score Out of } 5 \\
\text { Mean (SD) }\end{array}$ & $\begin{array}{c}\text { Practice Score Out of } 6 \\
\text { Mean (SD) }\end{array}$ \\
\hline \multicolumn{3}{|c|}{ Weight status (BMI in $\mathrm{kg} / \mathrm{m}^{2}$ ) } \\
\hline Underweight $(<18.5)$ & $3.20(0.72)$ & $1.74(0.82)$ \\
\hline Healthy weight (18.5-4.99) & $3.32(0.77)$ & $1.59(1.03)$ \\
\hline Overweight (25-29.99) & $3.16(0.80)$ & $1.71(0.99)$ \\
\hline Obese $(>30)$ & $3.31(0.72)$ & $2.04(0.96)$ \\
\hline$p$-value & 0.268 & $0.001 *$ \\
\hline \multicolumn{3}{|c|}{ Blood pressure $(\mathrm{mm} \mathrm{Hg}) *$} \\
\hline Normal $(<120 / 80)$ & $3.32(0.76)$ & $1.82(0.98)$ \\
\hline Elevated (systolic $120-129$ and diastolic $<80$ ) & $3.17(0.76)$ & $1.48(1.05)$ \\
\hline Stage 1 hypertension (systolic $130-139$ or diastolic $80-89$ ) & $3.31(0.72)$ & $1.73(1.03)$ \\
\hline Stage 2 hypertension (systolic $>140$ or diastolic $\geq 90$ ) & $3.12(0.84)$ & $1.85(0.92)$ \\
\hline$p$-value & 0.213 & 0.139 \\
\hline
\end{tabular}

SD: standard deviation; SR: Saudi Riyal (SR $3.75=\$ 1.00) ;{ }^{*}$ Values of $p<0.05$ were considered significant.

Multiple linear regression analysis revealed that salt-related practice scores were negatively associated with sodium intake and positively associated with BMI, whereas salt-related knowledge scores were not associated with sodium intake, blood pressure, or BMI (Table 4).

Table 4. Multiple linear regression analysis of salt-related knowledge and practice scores in relation to sodium intake, blood pressure, and body mass index (BMI).

\begin{tabular}{|c|c|c|c|c|c|c|}
\hline & Beta Estimate & Standard Error & $p$ & $95 \% \mathrm{CI}$ & $\mathbf{F}$ & R-Square \\
\hline \multicolumn{7}{|c|}{ Sodium intake (mg/day) } \\
\hline Salt-related knowledge & -88.3 & 163 & 0.588 & -408 to 232 & 2.38 & 0.01 \\
\hline Salt-related practices & -457 & 123 & $<0.001 *$ & -699 to -215 & 4.65 & 0.05 \\
\hline \multicolumn{7}{|c|}{ Systolic blood pressure (mm Hg) } \\
\hline Salt-related knowledge & -0.33 & 0.70 & 0.643 & -1.71 to 1.06 & 35.1 & 0.13 \\
\hline Salt-related practices & 0.39 & 0.55 & 0.480 & -0.69 to 1.46 & 14.9 & 0.14 \\
\hline \multicolumn{7}{|c|}{ Diastolic blood pressure (mm Hg) } \\
\hline Salt-related knowledge & -0.37 & 0.58 & 0.522 & -1.51 to 0.77 & 4.13 & 0.02 \\
\hline Salt-related practices & 0.35 & 0.45 & 0.444 & -0.54 to 1.23 & 1.80 & 0.02 \\
\hline \multicolumn{7}{|c|}{ BMI (BMI in $\left.\mathrm{kg} / \mathrm{m}^{2}\right)$} \\
\hline Salt-related knowledge & 0.60 & 0.36 & 0.119 & -0.15 to 1.26 & 9.74 & 0.04 \\
\hline Salt-related practices & 0.56 & 0.25 & $0.026^{*}$ & 0.07 to 1.05 & 28.2 & 0.23 \\
\hline
\end{tabular}

Models of salt-related knowledge were adjusted for sex; Models of practices related to salt were adjusted for age, sex, marital status, and city of residence; * Values of $p<0.05$ were considered significant.

\section{Discussion}

Limited salt-related knowledge and practices were observed among the study sample. Salt-related knowledge was not associated with sodium intake, blood pressure, or BMI, whereas practices related to salt intake were negatively associated with sodium intake and positively associated with BMI.

Our findings suggest that single individuals could have better practices related to salt intake, compared with married individuals. This differed from the findings of a previous study, in which no association was reported between marital status and increased sodium consumption [25]. In addition, females in our study reported better salt-related knowledge and practices than males. Similar findings were reported in a review conducted in 2018, in which females were found to have enhanced salt-related knowledge. The study also showed that females made greater effort to reduce sodium levels by reducing salt intake and buying less fast food [26]. In fact, women were found to be more health conscious overall and were more likely to read and follow nutritional recommendations than men $[27,28]$.

Findings of this study also suggest that older participants may have better salt-related practices than younger participants. These data are in accordance with the findings of previous studies, which 
have also shown that older people have better dietary practices [15,27-29]. Older individuals tend to be more health conscious, and that may be because health-related topics are less important to young individuals. As individuals age, their health declines and health-related topics become increasingly important [30].

Obesity or higher BMI of individuals included in this study was associated with better practices related to salt. In a study conducted in China, individuals who realized that they were at an increased risk of health consequences due to excessive sodium intake were more likely to prioritize the reduction of sodium intake [29]. Correspondingly, it has been reported that people who are aware of their current positive health status tend not to worry about salt intake [31].

No association between salt-related knowledge and sodium intake, blood pressure, or BMI was found in this study, which might reflect changes occurring in the Saudi diet. The Saudi diet has been influenced by urbanization, which has caused a shift from a traditional diet to a more westernized diet that is high in salt, added sugar, fat, and calories [32,33]. In addition, this lack of associations may indicate that the majority of individuals in the Saudi population have increased access to high-salt foods, such as processed or restaurant-prepared foods [32]. In fact, over $63 \%(n=295)$ of the participants included in this study consumed fast food more than twice a week. It is also possible that participants were unaware of the upper limits specified for sodium intake or failed to recognize that particular foods contain high levels of sodium, such as fast food [15].

A high level of awareness regarding diseases linked to excessive salt intake has been reported previously; however, despite this level of awareness, the intake of high levels of sodium persists [15,29]. This study reported limited salt-related knowledge as well as poor practices toward reducing salt intake. In addition, no correlation was found between salt-related knowledge and practices. This clearly indicates that salt-related knowledge may not be the only factor influencing practices related to salt intake. The association between salt-related knowledge and practices is complicated and may be influenced by several factors, including demographics, educational level, economic status, the environment, and culture [34-36].

To our knowledge, this is the first study to assess salt-related knowledge and practices among Saudi adults. However, the findings of this study might not be generalizable to the overall population of Saudi Arabia, as we performed convenience sampling. In this study, sodium intake was assessed by the FFQ. Despite the fact that the estimate of sodium intake that is obtained via a 24-h urine sample is considered the gold standard, the FFQ can provide a good estimate of the sodium intake of a group [21]. In addition, data concerning awareness regarding the food sources of sodium and the ability to read nutrition labels were not collected in this study.

\section{Conclusions}

Salt-related knowledge is limited and not linked to practices related to salt intake among Saudi adults. Our findings highlight the need of establishing interventions that aim to limit salt consumption by increasing the accessibility of low-sodium food options and improving practices related to salt intake. In fact, increasing public awareness regarding salt intake, using innovative approaches, may enforce the food industry to decrease the sodium content in food products.

Author Contributions: M.A.H. and W.A.M. conceived the study. W.A.M. conducted the analyses and interpreted the results. M.A.H. and W.A.M. wrote the first draft of the paper. All authors have read and agreed to the published version of the manuscript.

Funding: This research received no external funding.

Acknowledgments: We wish to thank all study participants for their time and collaboration throughout the data collection process. The authors thank Majed M Alkhalaf from the National Nutrition Committee in the Saudi Food and Drug Authority for providing the food frequency questionnaire used in this study. Thanks are due to Fatima Abdulhakeem for dedicating her time to assess in data collection, entry, and overall data management. Our sincere thanks are also extended to Ashraf Yousef Madadin from the Home Care Service Center in Madinah for their contribution during the collection of data. We would also like to thank all team members of the Salt Project for their assistance with data collection and entry. 
Conflicts of Interest: The authors declare no conflict of interest.

\section{References}

1. Alkhunaizi, A.M.; Al Jishi, H.A.; Al Sodah, Z.A. Salt Intake in Eastern Saudi Arabia. East. Mediterr. Heal. J. 2013, 19, 915-918. [CrossRef]

2. Brown, I.J.; Tzoulaki, I.; Candeias, V.; Elliott, P. Salt Intakes Around the World: Implications for Public Health. Int. J. Epidemiol. 2009, 38, 791-813. [CrossRef] [PubMed]

3. Mozaffarian, D.; Fahimi, S.; Singh, G.M.; Micha, R.; Khatibzadeh, S.; Engell, R.E.; Lim, S.; Danaei, G.; Ezzati, M.; Powles, J.; et al. Global Sodium Consumption and Death From Cardiovascular Causes. N. Engl. J. Med. 2014, 371, 624-634. [CrossRef] [PubMed]

4. World Health Organization. Diet, Nutrition and the Prevention of Chronic Diseases. World Health Organ. Tech. Rep. S. 2003. [CrossRef]

5. World Health Organization. WHO | Sodium Intake for Adults and Children. Available online: https:/www.who.int/elena/titles/guidance_summaries/sodium_intake/en/\#: \{\}:text=WHO\%20recommendations, \%2Fday\%20salt)\%20in\%20adults. (accessed on 27 June 2020).

6. Shaldon, S.; Vienken, J. Beyond the Current Paradigm: Recent Advances in the Understanding of Sodium Handling-Guest Editors: Stanley Shaldon and Joerg Vienken: Salt, the Neglected Silent Killer. Semin. Dial. 2009, 22, 252. [CrossRef]

7. World Health Organization. Salt Reduction. Available online: https://www.who.int/news-room/fact-sheets/ detail/salt-reduction\#;WorldHealthOrganization, 2020: \{\}:text=Salt\%20intake\%20of\%20less\%20than, stroke\%20and\%20coronary\%20heart\%20attack.\&text=WHO\%20Member\%20States\%20have\%20agreed, a\%20relative\%2030\%25\%20by\%202025 (accessed on 27 June 2020).

8. World Health Organization. Noncommunicable Diseases Progress Monitor 2015. 2015. Available online: https://www.who.int/nmh/publications/ncd-progress-monitor-2015/en/ (accessed on 27 June 2020).

9. American Heart Association. Shaking the Salt Habit to Lower High Blood Pressure. Available online: https://www.heart.org/en/health-topics/high-blood-pressure/changes-you-can-make-to-manage-highblood-pressure/shaking-the-salt-habit-to-lower-high-blood-pressure\#;AmericanHeartAssociation, 2020: $\sim\{\}:$ text $=$ The $\% 20$ American $\% 20$ Heart\%20Association \%20recommends, blood $\% 20$ pressure $\% 20$ and $\%$ 20heart\%20health (accessed on 27 June 2020).

10. Webster, J.L.; Dunford, E.K.; Neal, B.C. A Systematic Survey of the Sodium Contents of Processed Foods. Am. J. Clin. Nutr. 2010, 91, 413-420. [CrossRef]

11. Mattes, R.D.; Donnelly, D. Relative Contributions of Dietary Sodium Sources. J. Am. Coll. Nutr. 1991, 10, 383-393. [CrossRef]

12. Alhamad, N.; Almalt, E.; Alamir, N.; Subhakaran, M. An Overview of Salt Intake Reduction Efforts in the Gulf Cooperation Council Countries. Cardiovasc. Diagn. Ther. 2015, 5, 172-177. [CrossRef]

13. Moradi-Lakeh, M.; El Bcheraoui, C.; Afshin, A.; Daoud, F.; AlMazroa, M.A.; AlSaeedi, M.; Basulaiman, M.; Memish, Z.A.; Al Rabeeah, A.A.; Mokdad, A.H. Diet in Saudi Arabia: Findings From a Nationally Representative Survey. Public Heal. Nutr. 2017, 20, 1075-1081. [CrossRef]

14. Alawwa, I.; Dagash, R.; Saleh, A.; Ahmad, A. Dietary Salt Consumption and the Knowledge, Attitudes and Behavior of Healthy Adults: a Cross-Sectional Study From Jordan. Libyan J. Med. 2018, 13, 1479602. [CrossRef]

15. Nasreddine, L.; Akl, C.; Al-Shaar, L.; Almedawar, M.M.; Isma'eel, H. Consumer Knowledge, Attitudes and Salt-Related Behavior in the Middle-East: the Case of Lebanon. Nutrients 2014, 6, 5079-5102. [CrossRef] [PubMed]

16. Sarmugam, R.; Worsley, A.; Wang, W. An Examination of the Mediating Role of Salt Knowledge and Beliefs on the Relationship Between Socio-Demographic Factors and Discretionary Salt Use: a Cross-Sectional Study. Int. J. Behav. Nutr. Phys. Act. 2013, 10, 25. [CrossRef] [PubMed]

17. World Health Organization. Strategies to Monitor and Evaluate Population Sodium Consumption and Sources of Sodium in the Diet; Report of a Joint Technical Meeting Convened by WHO and the Government of Canada; World Health Organization, 2011; Available online: https://apps.who.int/iris/bitstream/handle/10665/44614/ 9789241501699_eng.pdf?sequence=1 (accessed on 27 June 2020). 
18. He, F.J.; MacGregor, G.A. Salt Reduction Lowers Cardiovascular Risk: Meta-Analysis of Outcome Trials. Lancet 2011, 378(9789), 380-382. [CrossRef]

19. Bibbins-Domingo, K.; Chertow, G.; Coxson, P.; Moran, A.; Lightwood, J.M.; Pletcher, M.J.; Goldman, L. Projected effect of dietary salt reductions on future cardiovascular disease. N Engl J Med. 2010, 362, 590-599. [CrossRef]

20. World Health Organization. Reducing Salt Intake in Populations: Report of a WHO Forum and Technical Meeting, 5-7 October 2006; World Health Organization: Paris, France, 2014. [CrossRef]

21. Alkhalaf, M.M.; Edwards, C.A.; Combet, E. Validation of a Food Frequency Questionnaire Specific for Salt Intake in Saudi Arabian Adults Using Urinary Biomarker and Repeated Multiple Pass 24-Hour Dietary Recall. Proc. Nutr. Soc. 2015, 74. [CrossRef]

22. World Health Organization. Global Health Observatory (GHO) Data: Mean Body Mass Index (BMI). Available online: https://www.who.int/gho/ncd/risk_factors/bmi_text/en/ (accessed on 27 June 2020).

23. Whelton, P.K.; Carey, R.M.; Aronow, W.S.; Casey, D.E., Jr.; Collins, K.J.; Himmelfarb, C.D.; DePalma, S.M.; Gidding, S.; Jamerson, K.A.; Jones, D.W.; et al. 2017 Guideline for the Prevention, Detection, Evaluation, and Management of High Blood Pressure in Adults a Report of the American College of Cardiology. Am. Heart Assoc. 2018, 71, e127-e248.

24. Ismail, L.C. Knowledge, Attitude, and Practice on Salt and Assessment of Dietary Salt and Fat Intake Among University of Sharjah Students. Nutrients 2019, 11, 941. [CrossRef]

25. Othman, F.; Ambak, R.; Siew Man, C.; Mohd Zaki, N.A.; Ahmad, M.H.; Abdul Aziz, N.S.; Baharuddin, A.; Salleh, R.; Aris, T. Factors Associated With High Sodium Intake Assessed From 24-Hour Urinary Excretion and the Potential Effect of Energy Intake. J. Nutr. Metab. 2019, 2019, 6781597. [CrossRef]

26. McKenzie, B.; Santos, J.A.; Trieu, K.; Thout, S.R.; Johnson, C.; Arcand, J.; Webster, J.; McLean, R. The Science of Salt: a Focused Review on Salt-Related Knowledge, Attitudes and Behaviors, and Gender Differences. J. Clin. Hypertens. (Greenwich) 2018, 20, 850-866. [CrossRef]

27. Webster, J.L.; Li, N.; Dunford, E.K.; Nowson, C.A.; Neal, B.C. Consumer Awareness and Self-Reported Behaviours Related to Salt Consumption in Australia. Asia Pac. J. Clin. Nutr. 2010, 19, 550-554. [CrossRef]

28. Dickson-Spillmann, M.; Siegrist, M. Consumers' Knowledge of Healthy Diets and Its Correlation With Dietary Behaviour. J. Hum. Nutr. Diet. 2011, 24, 54-60. [CrossRef] [PubMed]

29. Zhang, J.; Xu, A.Q.; Ma, J.X.; Shi, X.M.; Guo, X.L.; Engelgau, M.; Yan, L.X.; Li, Y.; Li, Y.C.; Wang, H.C.; et al. Dietary Sodium Intake: Knowledge, Attitudes and Practices in Shandong Province, China, 2011. PLOS ONE 2013, 8, e58973. [CrossRef] [PubMed]

30. Evans, M.; Cohen, J.; Kumanyika, S. Implementing Recommendations for Dietary Salt Reduction. Where Are We? Where Are We Going? How Do We Get There? A Summary of an NHLBI Workshop; DIANE Publishing: Bethesda, MD, USA, 1996.

31. Magalhães, P.; Sanhangala, E.J.R.; Dombele, I.M.; Ulundo, H.S.N.; Capingana, D.P.; Silva, A.B.T. Knowledge, Attitude and Behaviour Regarding Dietary Salt Intake Among Medical Students in Angola. Cardiovasc. J. Afr. 2015, 26, 57-62. [CrossRef] [PubMed]

32. Adam, A.; Osama, S.; Muhammad, K.I. Nutrition and Food Consumption Patterns in the Kingdom of Saudi Arabia. Pakistan J. of Nutrition 2014, 13, 181-190. [CrossRef]

33. Saeedi, M.; AlMadani, A.J.; Alsafi, Y.H.; Arif, S.H.; Mustafa, S.M.; Jamo, A.I. Estimation of Sodium and Potassium Intake in 24-Hours Urine, Aljouf Region, Northern Saudi Arabia. Chronic Dis. Int. 2017, 4, 1026.

34. Parmenter, K.; Waller, J.; Wardle, J. Demographic Variation in Nutrition Knowledge in England. Health Educ. Res. 2000, 15, 163-174. [CrossRef]

35. Dallongeville, J.; Marécaux, N.; Cottel, D.; Bingham, A.; Amouyel, P. Association Between Nutrition Knowledge and Nutritional Intake in Middle-Aged Men From Northern France. Public Health Nutr. 2001, 4, 27-33. [CrossRef]

36. Wardle, J.; Parmenter, K.; Waller, J. Nutrition Knowledge and Food Intake. Appetite 2000, 111, $1713-1726$. [CrossRef]

(C) 2020 by the authors. Licensee MDPI, Basel, Switzerland. This article is an open access article distributed under the terms and conditions of the Creative Commons Attribution (CC BY) license (http://creativecommons.org/licenses/by/4.0/). 